\title{
UTILIZATION OF HEALTH SERVICES REGARDING HEPATITIS B IN KARACHI, PAKISTAN: ACOMMUNITY SURVEY
}

\author{
Subhana Akber ${ }^{1,2}$, Laila Rizvi ${ }^{2}$, Saad Khalid Niaz ${ }^{2,3}$, Nighat Nisar $^{3}$ \\ ${ }^{1}$ Health Services Academy, Islamabad \\ ${ }^{2}$ The Health Foundation, Sharah-e-Faisal. Karachi, Pakistan. \\ ${ }^{3}$ Dow University of Health Sciences, Karachi Pakistan. \\ Correspondence: SubhanaAkber, Contact: +92 312 8661755, Email: subhanaakber@gmail.com
}

\begin{abstract}
Background: Hepatitis B virus (HBV) is considered as the smallest human DNA virus known to the world at present. Concerning the primary level of prevention against hepatitis $B$, health services utilization of community residents is essential to their health seeking behavior. This community-based study was designed to determine health services utilization regarding hepatitis $B$ among residents of Korangi, Karachi.

Methods: Across-sectional study design and multi-stage random sampling technique was used. Data was entered and analyzed in SPSS version-21. Sample size calculated at $95 \% \mathrm{Cl}$ with $5 \%$ absolute precision was 286 households. Data of 293 study respondents were entered for analysis after obtaining an informed consent. All participants were assured of their privacy and confidentiality to be protected. A pre-tested study questionnaire containing two main parts was administered to the study respondents.

Results: The results of our survey have elucidated that the residents of Korangi, Karachi were adherent to utilize health services regarding hepatitis $B$ which mainly included vaccination. A majority of the study participants reported to have their children vaccinated against hepatitis $B$ at their schools. Whereas, no significant association was observed for other covariates with health services utilization regarding hepatitis $\mathrm{B}$.

Conclusion: The findings of this survey have generally found that health services utilization regarding hepatitis $B$ was known to the community residents which can be attributed to better awareness. However, importance of screening and uptake of vaccination against hepatitis $B$ must be raised so as to reduce prevalence of disease in the community.
\end{abstract}

Keywords: Health utilization, health services, hepatitis and service delivery

\section{Introduction}

Hepatitis B affects millions of people causing acute and chronic liver disease all around the world.(1) The prevalence of hepatitis $B$ is $6.2 \%$ which is highest in the Western Pacific region whereas; in the Eastern Mediterranean region about $3.3 \%$ of the population is estimated to be affected. As ascertained, more than 2000 million people living at present are infected with HBV. Consequences of hepatitis B alone were responsible for more than 800 thousand deaths in 2015.(2) The World Health Assembly's resolution (WHA 63.182010 ) recognizes the importance of viral hepatitis as a global public health problem affecting hundreds of millions of lives and leaving them to disability or death by causing serious illness from acute or chronic hepatitis infection, liver cancer and liver cirrhosis. Following the resolution, WHO (2012) crafted a strategy that addresses four important components including raising awareness. According to the Global Policy Report on prevention and control of viral hepatitis, the variation in the five main types of hepatitis (A, B, C, D and E) that can manifest across and within geographical boundaries, global prevention and control efforts need to be defined in the country's national and sub-national prevention and control strategies.(3)

Gradual advancement in the methods of diagnosis, screening of blood donors, improvement in the health and hygienic standards, together with the availability of vaccine has greatly helped to reduce the prevalence of viral hepatitis around the world. But, still hepatitis $B$ virus (HBV) infection continues to be the global medical challenge in the developing part of the world. In Pakistan, clinical cases of chronic hepatitis B are a devastating problem. Since 1982, a vaccine against hepatitis B is available which is considered to be $95 \%$ effective in preventing HBV infection and its related outcomes.(2) In addition, hepatitis B vaccine is also considered as the first vaccine against a liver cancer.(4) Although, advancement in the modern medical knowledge about the contributory factors in acquiring the 
disease have greatly reduced the burden of this disease worldwide. However, there is still a need for improvement in providing awareness and knowledge about hepatitis $B$.

Vaccination against HBV is the most effective means of preventing and controlling the disease and its long-term sequelae in communities and masses. In 2002 , vaccine against hepatitis B was included in the childhood immunization schedule in Pakistan with the support from the GAVI Alliance.(4) Public health interventions particularly concerning over screening and vaccination in masses have proved to slow down the transmission of hepatitis B which needs more rigorous efforts. Largely, factors that have an impact on utilizing health services regarding hepatitis $B$ have been overlooked in research studies.(4) Considering the fact, it was perhaps important to determine health services utilization regarding hepatitis $\mathrm{B}$ of the community in order to prevent the disease in masses. Hence, the aim of this survey was to assess utilization pattern of health services regarding hepatitis $B$ among the community residents of Korangi, Karachi Pakistan. The specific objectives were to determine the vaccination status, willingness of the study respondents for free vaccination, their preference for acquiring hepatitis B prevention related information.

\section{Methodology}

This cross-sectional community-based study was conducted in Korangi which is located in the District East of Karachi, Pakistan. The whole population of Korangi resides in one compact area and the town houses have a mixed population. The study area constitutes of nine union councils and one cantonment area which was additionally included due to its close boundaries with other UC's. Hence, the entire population of Korangi town, Karachi was treated as a universe for this survey. All over time period of this research study is five months i.e. from August 2014 to December 2014.

A Multi-stage random sampling technique was employed for this survey. Sample size was estimated through WHO software (online). Using proportion of knowledge i.e. $24.6 \%$ as reported in an earlier study conducted in Pakistan (5), total projected population was taken into account with $5 \%$ absolute precision. Hence, a sample size at $95 \%$ confidence interval was calculated to be 286 participants. Thus, 300 participants were invited to participate in the study after being fully informed about the study aims, its objectives and their contribution to this survey. At initial stage, first five out of ten union councils were selected through simple random sampling (SRS). Using probability proportional to size sampling technique (PPS), each of the randomly selected union council was allocated a sample size of 60 households. In the second stage, sector / colonies were randomly selected. Following the second stage, every 25th household was systematically selected and a household member age above of 18 years, meeting the inclusion criteria was interviewed.
A semi-structured questionnaire was used as the study instrument which comprised of two main parts. Part A comprised of information related to the sociodemographic characteristics of the study participants. The second part $B$ of the questionnaire contained questions related to health services utilization regarding Hepatitis B. The study instrument was initially pretested, pre-validated on the same study population. The initial version of questionnaire was developed through extensive review of literature. It was also translated from English into Urdu (the national language of Pakistan) and was back translated into English. Length of time in each conducted interview was checked. Comprehension difficulties were assessed and the questionnaire was therefore refined accordingly. Also the reliability of the questionnaire was ensured. Before pre-testing the questionnaire, a detailed and specific plan for this survey was developed which included estimated budget needed for this survey, formation of the surveyors team, training of the data collectors, mapping of the study setting etc. The surveyors were assigned under each team for each of the union council (UC). Selection of the surveyors in the team was on the basis of their satisfactory knowledge about the study area and union councils.

It was ensured that all of these procedures were strictly followed according to the research methodology. The training sessions were conducted for a week. However, mapping was done along with each respective team after completion of the training sessions. After training and mapping, pre-testing of study instrument was conducted. Minor changes were required in the survey questionnaire which was then modified. Approximately, a total of 900 houses were approached for conducting the interview. Every 3rd in ten households refused to give consent thus, the non-response rate was $32.5 \%$.

The data were computed and analyzed by using Statistical Package for Social Sciences software (SPSS version-21). To minimize error data cleaning and validation was done. For quality assurance purpose, survey questionnaires were checked before leaving the randomly selected household and at the end of every day of data collection. For quantitative variables, descriptive analysis was performed and calculated. Associations between categorical variables were explored using Chi-square test. P-value of less than 0.05 was considered significant. Cleaning and coding of the data was done prior to analysis.

Data was collected after obtaining an ethical approval No. IRB-515/DUHS/-14 from the Institutional Review Board (IRB) of Dow University of Health Sciences, Karachi. The study was carried out as per the institutional and ethical guidelines for research studies involving human subjects.(5) An informed consent (both verbal and written) was obtained from each of the study participant. Participation was completely voluntary and anonymous. All research participants were assured of their privacy and confidentiality to be protected prior to 
interview.

\section{Results}

The mean age of the study respondents was $31.56 \pm$ 9.36 (mean \pm SD) years with $113(38.6 \%$ ) of individuals falling in 27-35 age group. Gender distribution was unequal as majority of females 248 (84.6\%) were being recruited in the survey through simple random sampling (SRS). Out of total number of respondents 244 (83.3\%) were married and $49(16.7 \%)$ were unmarried. Half of the married study participants $(50.8 \%)$ had ? 3 children. Less than half of study participants i.e. $123(42 \%)$ reported to have secondary level of education. Sixty nine $(42.3 \%)$ of the respondents had an income between 10,000 to 20,000 Pakistani rupees and 62 (38\%) earned below Rs. 10,000. Whereas, 130 of the total study participants did not mention their income status (table1).

Table 1: Socio-demographic Characteristics of the Study Respondents in Korangi, Karachi ( $N=293)$

\begin{tabular}{|c|c|c|c|c|}
\hline \multicolumn{3}{|c|}{ Characteristics } & Frequency (n) & Percentage (\%) \\
\hline \multirow{4}{*}{$\begin{array}{l}\text { Age } \\
(31.56 \pm 9.36)\end{array}$} & \multicolumn{2}{|l|}{$18-26$} & 94 & 32.1 \\
\hline & \multicolumn{2}{|l|}{$27-35$} & 113 & 38.6 \\
\hline & \multicolumn{2}{|l|}{$36-44$} & 50 & 17.0 \\
\hline & \multicolumn{2}{|l|}{ More than 44} & 36 & 12.3 \\
\hline \multirow{2}{*}{ Marital Status } & \multirow{2}{*}{\multicolumn{2}{|c|}{$\begin{array}{l}\text { Never Married } \\
\text { Married }\end{array}$}} & 49 & 16.7 \\
\hline & & & 244 & 83.3 \\
\hline \multirow{5}{*}{ Number of Children } & \multirow{2}{*}{ No Children } & Un Married & 49 & 17.1 \\
\hline & & Married & 21 & 7.2 \\
\hline & \multicolumn{2}{|l|}{$1-3$} & 122 & 41.2 \\
\hline & \multicolumn{2}{|l|}{$4-6$} & 74 & 25.3 \\
\hline & \multicolumn{2}{|l|}{ More than 6} & 27 & 9.2 \\
\hline \multirow{3}{*}{ Vaccination Status } & \multicolumn{2}{|l|}{ Vaccinated } & 76 & 25.9 \\
\hline & \multicolumn{2}{|c|}{ Un-Vaccinated } & 188 & 64.2 \\
\hline & \multicolumn{2}{|c|}{ Partially Vaccinated } & 29 & 9.9 \\
\hline \multirow{5}{*}{ Education } & \multicolumn{2}{|l|}{ Illiterate** } & 88 & 30.0 \\
\hline & \multicolumn{2}{|l|}{ Primary } & 22 & 7.5 \\
\hline & \multicolumn{2}{|l|}{ Secondary } & 123 & 42.0 \\
\hline & \multicolumn{2}{|l|}{ Intermediate } & 28 & 9.6 \\
\hline & \multicolumn{2}{|l|}{ Graduation } & 32 & 10.9 \\
\hline \multirow{4}{*}{ Income* } & \multirow{3}{*}{\multicolumn{2}{|c|}{$\begin{array}{l}\text { Less than } 10,000 \\
10,000-20,000 \\
\text { More than } 20,000\end{array}$}} & 62 & 21.2 \\
\hline & & & 69 & 23.7 \\
\hline & & & 32 & 10.9 \\
\hline & \multicolumn{2}{|c|}{ Did not declare } & 130 & 44.2 \\
\hline \multirow{2}{*}{ Occupation } & \multirow{2}{*}{\multicolumn{2}{|c|}{$\begin{array}{l}\text { Unemployed } \\
\text { Employed }\end{array}$}} & 163 & 55.6 \\
\hline & & & 130 & 44.4 \\
\hline
\end{tabular}

${ }^{*}$ Pakistani Rupees ** No formal education

Among those study respondents who were unemployed (163, 55.6\%), mainly were housewives 146 (49.8\%) followed by $4.1 \%$ students $(n=12)$ and others. The employed category included $13 \%$ (38) respondents who owned a business / shop second to $22.4 \% \quad(n=66)$ of individuals who manual workers. Lastly, a large portion of the study participants i.e. $188(64.2 \%)$ were unvaccinated against hepatitis B, $76(25.9 \%)$ were vaccinated and $29(9.9 \%)$ reported to be partially vaccinated against hepatitis B as shown in Figure 1.

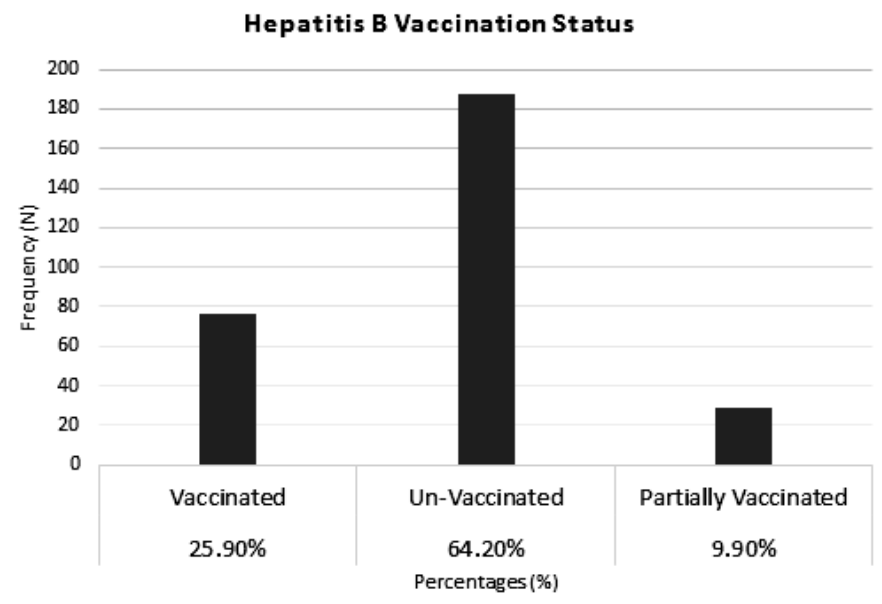

Figure 1. Vaccination Status of the Study Participants Assessment of Health Services Utilization regarding Hepatitis $B$ among study participants

Regarding the utilization of healthcare services for hepatitis B by the community, almost $53.6 \%(n=157)$ of the survey participants responded positively about knowing the healthcare facility located in their respective areas where they can get vaccinated against hepatitis $B$. Majority of the research participants $211(74 \%)$ reported to have vaccinated their children against hepatitis B. However, $26 \%(n=74)$ of those respondents who had not vaccinated their children against HBV exposed multiple reasons for not doing so, with highest reported frequency i.e. $34(11.6 \%)$ revealed to have 'No Reason' as shown in Figure 2.

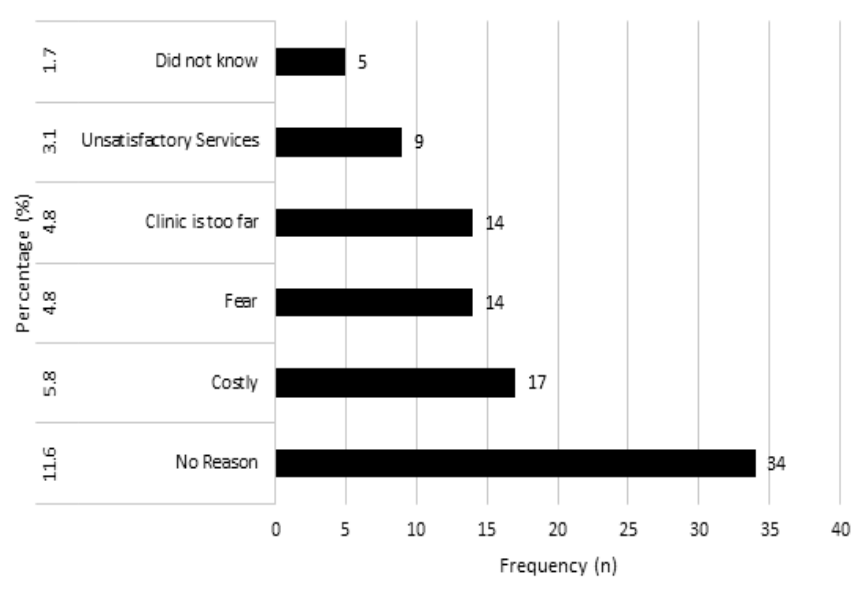

Figure 2 Multiple Reported Reasons for UnVaccinating Children against HBV

Out of all survey respondents, 116 (89.2\%) were convinced to get their children vaccinated against HBV at their schools (Figure 3 ). These participants mainly included those who were married either having no children or who had not vaccinated their children against hepatitis $\mathrm{B}$ (table 2 ). 
Table 2: Effect of Socio-demographic Characteristics on Health Services Utilization regarding Hepatitis B

\begin{tabular}{|c|c|c|c|c|c|c|c|c|c|}
\hline Variables & & Determi & iants 0 & Healtl & Services & tilization & egard & g Hepat & \\
\hline \multirow{3}{*}{$\begin{array}{l}\text { Gender } \\
\text { Male } \\
\text { Female }\end{array}$} & \multicolumn{3}{|c|}{$\begin{array}{l}\text { Knowledge about } \\
\text { healthcare facility }\end{array}$} & \multicolumn{3}{|c|}{$\begin{array}{c}\text { Preference for } \\
\text { vaccination at schools }\end{array}$} & \multicolumn{3}{|c|}{$\begin{array}{l}\text { Willingness for free } \\
\text { vaccination }\end{array}$} \\
\hline & & $\begin{array}{c}\text { Crude } \\
\text { OR } \\
(95 \% \\
\text { CI })\end{array}$ & $\begin{array}{c}\text { p- } \\
\text { value }\end{array}$ & & $\begin{array}{c}\text { Crude } \\
\text { OR } \\
(95 \% \\
\text { CI })\end{array}$ & p-value & & $\begin{array}{c}\text { Crude } \\
\text { OR } \\
(95 \% \\
\text { CI })\end{array}$ & p-value \\
\hline & $\begin{array}{c}34 \\
178\end{array}$ & $\begin{array}{c}0.73 \\
(0.38- \\
1.40) \\
1\end{array}$ & $\begin{array}{c}0.34 \\
-\end{array}$ & $\begin{array}{c}44 \\
231\end{array}$ & $\begin{array}{c}0.46 \\
(0.13- \\
1.58) \\
1\end{array}$ & $\begin{array}{c}0.04 \\
-\end{array}$ & $\begin{array}{c}31 \\
209\end{array}$ & $\begin{array}{c}0.46 \\
(0.13- \\
1.58) \\
1\end{array}$ & $\begin{array}{c}0.04 \\
-\end{array}$ \\
\hline $\begin{array}{l}\text { Marital } \\
\text { Status } \\
\text { Never } \\
\text { Married } \\
\text { Married }\end{array}$ & $\begin{array}{c}30 \\
182\end{array}$ & $\begin{array}{c}1 \\
1.28 \\
(0.71- \\
2.31)\end{array}$ & $\begin{array}{c}- \\
0.39\end{array}$ & $\begin{array}{c}45 \\
230\end{array}$ & $\begin{array}{c}1 \\
0.54 \\
(0.21- \\
2.16)\end{array}$ & 0.71 & $\begin{array}{c}34 \\
206\end{array}$ & $\begin{array}{c}1 \\
0.52 \\
(0.23- \\
1.19)\end{array}$ & 0.05 \\
\hline $\begin{array}{l}\text { Occupation } \\
\text { Employed } \\
\text { Unemployed }\end{array}$ & $\begin{array}{l}102 \\
110\end{array}$ & $\begin{array}{c}0.73 \\
(0.04- \\
12.29) \\
1\end{array}$ & $\begin{array}{c}0.83 \\
-\end{array}$ & $\begin{array}{l}153 \\
122\end{array}$ & $\begin{array}{c}0.56 \\
(0.68- \\
4.90) \\
1\end{array}$ & $\begin{array}{c}0.69 \\
-\end{array}$ & $\begin{array}{l}136 \\
104\end{array}$ & $\begin{array}{c}0.59 \\
(1.44- \\
1.34) \\
1\end{array}$ & $\begin{array}{c}0.55 \\
-\end{array}$ \\
\hline
\end{tabular}

${ }^{*}$ Pvalue was calculated by logistic regression and ?0.05 level was taken as significant.

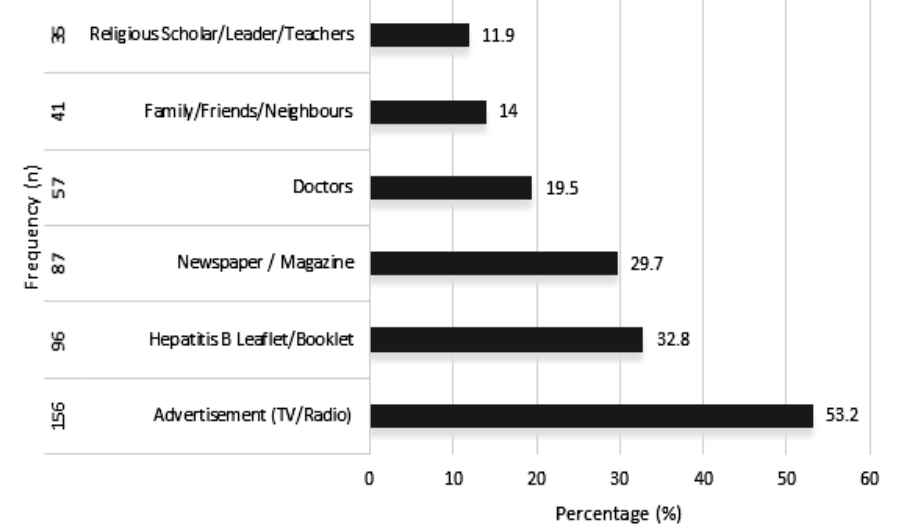

Figure 3: shows various reported sources of preference for prevention related information regarding hepatitis

Association of Socio-Demographic Characteristics with Health Services Utilization

Association of socio-demographic characteristics with health services utilization of these community residents was explored using Pearson's correlational analysis with a p-value of ? 0.05 and $95 \%$ of $\mathrm{Cl}$ taken as significant. Univariate analysis elucidated that gender and marital status were found to be insignificantly associated with knowledge about healthcare facility in the area (OR = $0.73,95 \% \mathrm{Cl}: 0.38-1.40$, p-value 0.34$)$ and $(\mathrm{OR}=1.28$, $95 \% \mathrm{Cl}$ : 0.71-2.31, p-value 0.39);perception of study participants about preventing themselves against hepatitis B if were sufficiently informed about it(OR = $1.23,95 \% \mathrm{Cl}: 0.93-2.54$, p-value $? 0.05)$ and $(\mathrm{OR}=3.52$,
95\% Cl: 0.00-1.56, p-value 0.68); and willingness to get free vaccinated against hepatitis B $(\mathrm{OR}=0.46,95 \% \mathrm{Cl}$ : $0.13-1.58$, p-value 0.22$)$ and $(\mathrm{OR}=0.76,95 \% \mathrm{Cl}: 0.32-$ 1.74 , p-value 0.51 ) respectively. In addition, occupation had an insignificant association with knowledge about the healthcare facility located in the study area (OR = 0.73, 95\% Cl: 0.04-12.29, p-value 0.83). Moreover, gender was found $54 \%$ less likely to be associated with preference of study participants to get their children vaccinated at their schools $(\mathrm{OR}=0.46,95 \% \mathrm{Cl}$ : 0.13 $1.58, p$-value ?0.05). Whereas, a large majority of study participants were two times more likely to have their children vaccinated against hepatitis B although it was found to have an insignificant association with gender, marital status, education, occupation; and vaccination status of the study respondents $(A O R=2.34,95 \% \mathrm{Cl}$ : $0.46-11.82$, p-value 0.14 ) on multivariate analysis.

\section{Discussion}

The result findings of our survey indicates that residents of Korangi, Karachi have adequate level of health services utilization regarding hepatitis $B$ which can be an impact of better awareness regarding hepatitis $B$, its mode of acquisition and transmission routes. Considering the vaccination status of the study participants, a considerable majority were found to be unvaccinated against hepatitis $B$ which is parallel to the findings of studies conducted among Asian Americans, Chinese population and in Pakistan.(5-8) According to the findings of Qureshi et.al, (2014), it is argued that three doses of hepatitis $B$ vaccine does not sufficiently provides protection against hepatitis B.(9)A similar study evaluating hepatitis $B$ vaccine was conducted among healthy young women volunteers in Karachi. The results revealed that licensed vaccine against hepatitis $B$ which are available in Pakistan have high immunogenicity and adequate tolerability.(10) However; much rigorous studies are needed in order to validate the true effects of vaccination against $\mathrm{HBV}$ in the communities and at the country level.

Considering the health services utilization pattern in this community of Karachi, more than $50 \%$ of the study participants confirmed to know about the healthcare facility located in their respective areas where they can get vaccinated against hepatitis $B$. In addition, those respondents of our study who had not vaccinated their children against HBV revealed to have 'no reason' followed by the 'cost of vaccination' and 'mistrust on health services' (Figure 2) that held them from vaccinating their children against HBV which is consistent to the findings of other studies.(11-13) However, almost all the participants of our study showed their willingness to get vaccinated against HBV and to prevent themselves and their family members against hepatitis B if provided with sufficient information and education related to it. Thus, these findings are highly important in considering the efficacy and effectiveness of other related immunization and prevention programs on community as well as provincial level in Pakistan. 
Studies conducted among the Asian Americans, Vietnamese Americans and Chinese immigrants in the United States aimed to assess screening and vaccination practices of the study respondents against hepatitis $B$ has also reported unsatisfactory results which is consistent to the finding of our survey. $(14,15)$ It can be therefore proposed that adequate awareness regarding hepatitis $\mathrm{B}$ and importance of prevention against it should be fostered and implemented as an adjunct to education and health promotion campaigns in the region. Although, impact of education and raising awareness regarding hepatitis $B$ is equally important but actual success is in enhancing the utilization of health services regarding hepatitis $B$ among the community residents of Korangi, Karachi.

\section{Conclusion}

The findings of this study clearly concludes that the community residents of Korangi, Karachi have encouraging health seeking behavior towards hepatitis $B$. Generally, the health services utilization regarding hepatitis B was adequate among the study participants. However, rigorous studies evaluating the need, pattern and mode to access the health services should be conducted in order to strengthen health system at primary care level.

\section{Competing Interests}

The authors declare that they have no competing interests.

\section{Acknowledgement}

The authors thank all the participants of study as well as the surveyors for their contribution.

\section{References}

1. Centers for Disease Control and Prevention. Hepatitis B Information | Division of Viral Hepatitis | CDC. CDC. 2015 [cited 2018 Apr 9]. Available from: https://www.cdc.gov/hepatitis/ hbv/index.htm

2. World Health Organization. WHO Hepatitis B [Internet]. WHO. World Health Örganization; 2017 [cited 2018 Apr 9]. Available from: http://www.who.int/mediacentre/factsheets/fs20 4/en/

3. Lazarus J V, Safreed-Harmon K, Sperle I. Global policy report on the prevention and control of viral hepatitis: In WHO Member States. Glob Alert Response. 2013.

4. Blanton JD, Robertson K, Palmer D, Rupprecht $\mathrm{CE}$. Rabies surveillance in the United States during 2008. Public Vet Med Public Heal. 2009.

5. UI Haq N, Hassali MA, Shafie AA, Saleem F, Farooqui $\mathrm{M}$, Aljadhey $\mathrm{H}$. A cross sectional assessment of knowledge, attitude and practice towards Hepatitis B among healthy population of Quetta, Pakistan. BMC Public Health. 2012.

6. Chung PW, Suen SH, Chan OK, Lao TH, Leung TY. Awareness and knowledge of hepatitis $B$ infection and prevention and the use of hepatitis $B$ vaccination in the Hong Kong adult Chinese population. Chin Med J (Engl). 2012.

7. Taylor VM, Talbot J, Do HH, Liu Q, Yasui Y, Jackson JC, et al. Hepatitis B knowledge and practices among Cambodian Americans. Asian Pac J Cancer Prev. 2011.

8. Wu C a., Lin SY, So SK, Chang ET. Hepatitis b and liver cancer knowledge and preventive practices among asian americans in the san francisco bay area, california. Asian Pacific J Cancer Prev. 2007 [cited 2018 Apr 9];8(1):12734.

9. Qureshi H. The evidence of mother to child transmission of hepatitis $b$ virus infection in Pakistan and the need for hepatitis $B$ immunization policy change. Vol. 64, Journal of the Pakistan Medical Association. 2014 [cited 2018 Apr 9]. p. 978.

10. Hakim S. Comparative Evaluation of Four Hepatitis B vaccines available in Pakistan: Reactogenecity and Immunogenecity Reactogenecity and Immunogenecity. BJMP [Internet]. 2009 [cited 2018 Apr 9];64(8):978.

11. Larson HJ, Cooper LZ, Eskola J, Katz SL, Ratzan S. Addressing the vaccine confidence gap. Lancet [Internet]. 2011 Aug 6 [cited 2018 Apr 9];378(9790):526-35.

12. Rainey JJ, Watkins M, Ryman TK, Sandhu P, Bo A, Banerjee K. Reasons related to nonvaccination and under-vaccination of children in low and middle income countries: Findings from a systematic review of the published literature, 1999-2009. Vaccine [Internet]. 2011 Oct 26 [cited 2018 Apr 9];29(46):8215-21.

13. Brand J. attitudes, beliefs and behaviors related to vaccination and testing practices for seasonal influenza and viral hepatitis B \& $C$ in Native American populations residing in. 142nd APHA Annu Meet Expo ( . ... 2014

14. Ma GX, Shive SE, Fang CY, Feng Z, Parameswaran L, Pham A, et al. Knowledge, Attitudes, and Behaviors of Hepatitis B Screening and Vaccination and Liver Cancer Risks Among Vietnamese Americans. J Health Care Poor Underserved [Internet]. 2007 [cited 2018 Apr 9];18(1):62-73.

15. Hwang JP, Huang $\mathrm{CH}$, Yi JK. Knowledge about hepatitis $B$ and predictors of hepatitis $B$ vaccination among Vietnamese American college students. J Am Coll Heal. 2008 Jan [cited 2018Apr 9];56(4):377-82. 